\title{
ADAT PERKAWINAN BUDAYA BUGIS MAKASSAR \\ DAN RELEVANSINYA DALAM ISLAM
}

\author{
Oleh, Sudirman $\mathbf{P}^{1}$.
}

\begin{abstract}
Abstrak,
Perkawinan merupakan suatu peristiwa yang sangat penting dalam kehidupan manusia. Dalam ajaran Islam pun kita di anjurkan untuk menikah, Al-Qur'an pun menjelaskan dalam surah Az-Zariyah ayat 49, dan surah yasin ayat 36, bahwa manusia telah diciptakan dalam bentuk pasangan-pasangan, baik dari apa yang ditumbuhkan oleh bumi dan dari diri mereka maupun dari apa yang tidak mereka ketahui.

Tujuan perkawinan menurut agama islam ialah untuk memenuhi petunjuk agama dalam rangka mendirikan keluarga yang harmonis, sejahtera dan bahagia. Harmonis dalam menggunakan hak dan kewajiban anggota keluarga, sehinggah timbullah kebahagiaan, yakni kasih sayang angtar anggota keluarga. Begiru pula dalam budaya Bugis Makassar perkawinan adalah salah satu cara untuk melanjutkan keturunan dengan dasar cinta kasih untuk melanjutkan hubungan yang erat angtara keluarga yang lain, angtara suku dan suku yang lain bahkan angtara bangsa dengan bangsa lain.

Budaya dan adat perkawinan Bugis Makassar adalah salah satu budaya pernikahan di Indonesia yang paling kompleks dan melibatkan banyak emosi. Bagaimana tidak, mulai dari ritual lamaran hingga selesai resepsi pernikahan akan melibatkan seluruh keluarga yang berkaitan dengan kedua pasangan calon mempelai. Ditambah lagi dengan biaya mahar dan "Doi' Panaik atau uang naik atau biaya akomodasi pernikahan yang selangit. Sebenarnya dulu adat budaya pernikahan yang tergolong mewah ini hanya berlaku bagi keluarga kerajaan, namun sekarang mengalami pergeseran dan mulai dipraktekkan masyarakat umum suku Bugis Makassar

Dalam budaya adat Bugis Makassar juga dikenal pula perkawinan ideal dan pembatasan jodoh yaitu perkawinan angtara Sampo Sikali (sepupu satu kali), hubungan perkawinan ini disebut sialleang baji'na (perjodohan yang paling baik), perkawinan angtara Sampo Pinruang (sepupu dua kali), hubungan perkawinan ini disebut nipassikaluki, perkawinan angtara sampo pintallu (sepupu tiga kali), dan seterusnya. hubungan perkawinan ini disebut nipakambani bellayua (yang jauh didekatkan). Dalam budaya adat Bugis Makassar ada beberapa bentuk-bentuk perkawinan, mulai dalam bentuk peminangan, perkawinan dengan annyala, silariang, nilariang,dan erangkale.

Upacara perkawinan di daerah Sulawesi Selatan banyak dipengaruhi oleh ritual-ritual sakral dengan tujuan agar perkawinan berjalan dengan lancar dan kedua mempelai mendapat berkah dari Tuhan. Semua itu dilakukan mempunyai makna dan kepercayaan tersendiri.
\end{abstract}

Kata Kunci: Adat, Perkawinan, Islam, Bugis Makassar.

\section{A. Pendahuluan}

Perkawinan merupakan suatu peristiwa yang sangat penting dalam kehidupan manusia. Dasar-dasar perkawinan dibentuk oleh unsur-unsur alami dari kehidupan manusia itu sendiri yang meliputi kebutuhan dan fungsi biologis, melahirkan keturunan,

\footnotetext{
${ }^{1}$ Dosen Tetap IAI Muhammadiyah Sinjai
} 
kebutuhan akan kasih sayang dan persaudaraan, memelihara anak-anak tersebut menjadi anggota-anggota masyarakat yang sempurna (volwaardig). ${ }^{2}$

Bagi para pemeluk agama, perkawinan bersifat sakral yang mengandung ajaranajaran agama bagi para pemeluknya. Ritual perkawinan tidak hanya dipandang sebagai peristiwa sakral. Setelah selesai ritual sakral, timbullah ikatan perkawinan antara suami dan isteri. ${ }^{3}$ Begitu juga dengan Budaya dan adat perkawinan Bugis Makassar adalah salah satu budaya pernikahan di Indonesia yang paling kompleks dan melibatkan banyak emosi. Bagaimana tidak, mulai dari ritual lamaran hingga selesai resepsi pernikahan akan melibatkan seluruh keluarga yang berkaitan dengan kedua pasangan calon mempelai. Ditambah lagi dengan biaya mahar dan 'Doi' Panaik atau uang naik atau biaya akomodasi pernikahan yang selangit. Sebenarnya dulu adat budaya pernikahan yang tergolong mewah ini hanya berlaku bagi keluarga kerajaan, namun sekarang mengalami pergeseran dan mulai dipraktekkan masyarakat umum suku Bugis Makassar.

Berdasarkan latar belakan di atas maka pemakalah akan membahas tentang budaya adat pernikahan bugis makassar dan kami mencoba untuk kolaborasikan angtara budaya pernikahan dalam islam.

\section{B. PEMBAHASAN}

1. Sikap Agama Islam Terhadap Perkawinan

Dalam Al-Qur'an dinyatakan bahwa hidup berpasang-pasangan, hidup berjodohjodoh adalah naluri segala mahluk Allah, sebagaimana firmanya dalam surah AzZariyah ayat 49:

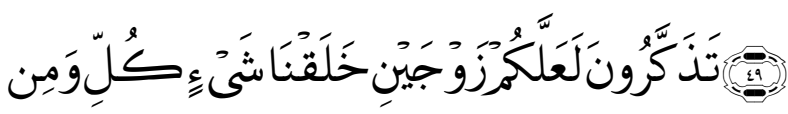

Artinya: Dan segala sesuatu kami ciptakan berpasang-pasangan supaya kamu mengingat dan kebesaran Allah Swt. ${ }^{4}$

Dalam surat yasin ayat 36 dinyatakan:

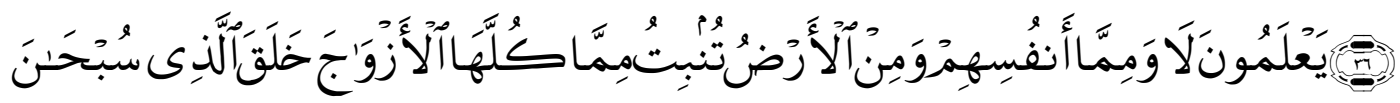
hal. 2 .

${ }^{2}$ Titik Triwulan dan Trianto, Poligami Perspektif, Perikatan Nikah, (Jakarta : Prestasi Pustaka, 2007),

${ }^{3}$ Cholil Mansyur, Sosiologi Masyarakat Kota dan Desa, (Surabaya : Usaha Nasional, 1994),Hal. 19.

${ }^{4}$ Departemen Agama RI, Al-Qur'an dan Terjemahanya, CV Penerbit J-ART, Bandun, 2005, hlm 522 
Artinya: Maha Suci Tuhan yang telah menciptakan pasangan-pasangan semuanya, baik dari apa yang ditumbuhkan oleh bumi dan dari diri mereka maupun dari apa yang tidak mereka ketahui. ${ }^{5}$

Dari mahluk yang diciptakan oleh Allah SWT berpasang-pasangan inilah Allah SWT menciptakan manusia menjadi berkembang biak dan berlangsung dari generasi-ke generasi berikutnya. Islam mengatur manusia dalam hidup berjodohjodohan itu melalui jenjang perkawinan yang ketentuanya dirumuskan dalam ujud aturan-aturan yang disebut hukum perkawinan dalam.

Hukum islam juga ditetapkan untuk kesejahteraan umat, baik secara perorangan maupun secara bermasyarakat, baik untuk hidup di dunia maupun di akhirat. Kesejahteraan masyarakat akan tercapai dengan terciptanya kesejahteraan, karena keluarga merupakan lembaga terkecil dalam masyarakat, sehinggah kesejahteraan masyarakat sangat tergantun dari kesejahteraan keluarga. ${ }^{6}$

Tujuan perkawinan menurut agama islam ialah untuk memenuhi petunjuk agama dalam rangka mendirikan keluarga yang harmonis, sejahtera dan bahagia. Harmonis dalam menggunakan hak dan kewajiban anggota keluarga; sejahtera artinya terciptanya ketenangan lahir dan batinya, sehinggah timbullah kebahagiaan, yakni kasih sayang angtar anggota keluarga. ${ }^{7}$ Manusia diciptakan Allah SWT mempunyai naluri manusiawi yang perlu mendapat pemenuhan. Dalam pada itu manusia diciptakan oleh Allah SWT untuk mengabdikan dirinya kepada khaliq penciptanya dengan segala aktivitas hidupnya. Pemenuhan naluri manusiawi manusia yang angtara lain keperluan biologisnya termasuk aktivitas hidup, agar manusia menuruti tujuan kejadianya, Allaw SWT mengatur hidup manusia dengan aturan perkawinan.

Jadi aturan perkawinan menurut islam merupakan tuntunan agama yang perlu mendapat perhatian, sehinggah tujuan melangsungkanya perkawinan pun hendaknya ditujukan untuk memenuhi petunjuk agama. Sehinggah kalau diringkas ada dua tujuan orang melangsungkan perkawinan ialah memenuhi nalurinya dan memenuhi petunjuk agama. $^{8}$

\footnotetext{
${ }^{5}$ Ibid, hlm.442

${ }^{6}$ Abdul Rahman, Fiqh Munakahat,(Cet, IV, Jakarta: Kencana, 2010), hlm. 22

${ }^{7}$ Ibid, hlm. 13

${ }^{8}$ Ibid, hlm. 22.
} 
Peminangan merupakan pendahuluan perkawinan, disyariatkan sebelum ada ikatan suami istri dengan tujuan agar waktu memasuki perkawinan didasarkan kepada penelitian dan pengetahuan serta kesadaran masing-masing pihak. ${ }^{9}$

Adapun perempuan yang boleh dipinang adalah yang memenuhi syarat-syarat sebagai berikut:

a. Tidak dalam pinangan orang lain

b. Pada waktu dipinang tidak ada penghalang syar'i yang melarang melangsungkanya pernikahan.

c. Perempuan itu tidak masa iddah karna talak raj'i

d. Apabila perempuan dalam masa iddah karna talak ba'in, hendaklah meminan dengan cara sirry (tidak terang-terangan). ${ }^{10}$

\section{Adat Pernikahan Budaya Bugis Makassar}

a. Tujuan Perkawinan Menurut Adat

Perkawinan mempunyai arti yang sangat penting, dan bukan hanya sekedar untuk memenuhi hasrat seksual. Perkawinan adalah salah satu cara untuk melanjutkan keturunan dengan dasar cinta kasih untuk melanjutkan hubungan yang erat angtara keluarga yang lain, angtara suku dan suku yang lain bahkan angtara bangsa dengan bangsa lain.

Menelah uraian tersebut maka perkawinan itu seolah-olah wajib, pandangan yang demikian pula tersimpul dalam ucapan atau ungkapan orang Makassar yang mengatakan" Tenapa nagarna se're tau punna tenapa nasi tuttu ulunna salangganna (seseorang belum sempurna jikalau kepalanya belum berhubungan dengan bahunya. Pengertian dan ucapan ini adalah bahwa manusia baru dapat manusia sempurna yang dalam bahasa Makkassar disebut tau bila ia sudah kawin. Seseorang yang belum kawin duimpamakan mempunyai tubuh yang belum lengkap karna kepala dan selangkahnya (tubuhnya) dianggap belum berhubungan suami dan istri dipersamakan sebagai kepala dan badan yang harus dihubungkan untuk menjadi manusia yang sempurna. ${ }^{11}$

Hubungan perkawinan itu menyebabkan kedua keluarga terikat oleh suatu ikatan yang disebut Ajjuluk Sirik, maksudnya kedua keluarga bersatu dalam mendukung kehormatan keluarga. Orang yang tidak berketurunan disebut tau

\footnotetext{
${ }^{9}$ Ibid, hlm. 74

${ }^{10}$ Ibid,

${ }^{11}$ Dinas Kebudayaan dan Parawisata Propinsi Sulawesi Selatan, Adat dan Upacara Perkawinan Daerah Sulawesi Selatan. 2006. Hlm. 23.
} 
puppusuk, artinya orang yang tidak berkembang biak dan termasuk orang sial. Terhadap seseorang yang banyak anak dikatakan kalumannyangmako kajaimi anaknu artinya engkau sudah kaya karna anakmu sudah banyak, anak itu pembawa rezeki. ${ }^{12}$

3. Perkawinan Ideal dan Pembatasan Jodoh

Pertimbangan-pertimbangan dalam mencari jodoh adalah masalah "Kasiratangang " (Siratang=sepadan, bersamaan) dalam kedudukan sosial, Kasiratangang ialah hubungan sejajar dan sepadan yang tidak akan menimbulkan goncangan dalam masyarakat. Menurut anggapan orang Makassar perkawinan yang ideal, perkawinan dalam lingkungan kerabat utamanya dalam lingkungan kerabat yang berada dalam garis horisontal sebagai berikut:

a. Perkawinan angtara Sampo Sikali (sepupu satu kali), hubungan perkawinan ini disebut sialleang baji'na (perjodohan yang paling baik).

b. Perkawinan angtara Sampo Pinruang (sepupu dua kali), hubungan perkawinan ini disebut nipassikaluki.

c. Perkawinan angtara sampo pintallu(sepupu tiga kali), dan seterusnya. hubungan perkawinan ini disebut nipakambani bellayua (yang jauh didekatkan). ${ }^{13}$

Pembatasan jodoh dalam makalah ini dapat disebabkan karena berada dalam hubungan tena nasiratang, maksudnya tidak sepadan dalam kedudukan sejajar, akan tetapi prinsip ini sudah berubah sesuai dengan perkembangan masyarakat, oleh sebab pembatasan jodoh yang sesungguhnya dimaksud ialah hubungan perkawinan yang tidak wajar yang disebut Salimarakyang dalam istilah anthropologi disebut incest atau sumbang ialah larangan perkawinan angtara; Ibu kandung, bapak kandung, ibu dari ibu kandung, bapak dari bapak kandung, anak-anak laki-laki atau perempuan, saudarasaudara baik laki-laki atau perempuan, saudara dari ibu, anak saudara, cucu saudara, ibu tiri, bapak tiri, mertua dan menantu. ${ }^{14}$

4. Bentuk-Bentuk Perkawinan

a. Perkawinan dengan peminangan

Bentuk perkawinan dengan peminangan ini berlaku umum baik dari golongan bangsawan maupun dari golongan biasa. Hanya golongan bangsawan banyak melalui proses-proses dan upacara-upacara adat tertentu. Apabila telah terjadi

\footnotetext{
${ }^{12}$ Petadungan dan kk, Catatan Perkawinan. Tahun 1969.

${ }^{13}$ Dinas Kebudayaan dan Parawisata.....Hlm. 25

${ }^{14}$ Ibid, Hlm 26
} 
kesepakatan dalam peminangan, maka hubungan kedua calon pengaantin ini disebut abbayuang atau bertunangan. Cara perkawinan dengan peminangan ini adalah suatu cara adat untuk menjamin terciptanya keluarga yang diterima umum dalam lingkungan keluarga maupun masyarakat. ${ }^{15}$

b. Perkawinan dengan "Annyala".

Annyala berarti berbuat salah, dalam hal ini berbuat salah terhadap adat perkawinan yang diwujudkan dengan kawin lari. Dengan peristiwa itu, maka timbullah ketegangan dalam masyarakat, terutama keluarga gadis yang lari atau dibawa lari. ${ }^{16}$

Sebab umum daripada peristiwa annyala ini ialah karna yang bersangkutan tidak dapat melakukan syarat-syarat terlaksananya perkawinan adat sehinggah mereka berusaha melakukan perkawinan diluar tata cara perkawinan adat dengan jalan annyala. Bila Tu-Mannyala telah berada dirumah salah satu pemuka masyarakat (dalam hal ini imam atau kadhi), maka menjadi kewajiban baginya untuk segera menikahkan tu-mannyala. Selanjutnya setelah imam atau kadhi mengawinkan Tu-Mannyalatadi bukanlah berarti bahwa ketegangan dalam masyarakat telah pulih karna peristiwa adatnya belum selesai.

Hubungan angtara tu-masirik dengan Tu-Mannyala sebagai tuappakasiriktetap tegang, dan dendam tu-masirikakan terus berlangsung selama TuMannyala belum abbajikartinya damai.

Annyala ada beberapa macam:

\section{Silariang}

Silariang berarti sama-sama lari, jadi terjadinya adalah karena kehendak bersama setelah mengadakan mufakat secara rahasia. Kemudian menetapkan waktu untuk bersama menuju rumah penghulu adat (imam atau kadhi) meminta perlindungan dan selanjutnya untuk dinikahkan.

Adapun sebab-sebab khusus terjadinya silariang adalah:

a. Karena sigadis telah mempunyai tambatan hati dengan seorang lelaki, lalu ia akan dikawinkan dengan seseorang yang tidak dicintainya yang merupakan suatu paksaan baginya.

b. Keduanya telah salin cinta mencintai, akan tetapi lelaki tidak mampu untuk melaksanakan tuntutan pihak keluarga gadisnya.

\footnotetext{
${ }^{15}$ Ibid, Hlm 27

${ }^{16} \mathrm{Ibid}, \ldots .$.
} 
c. Karena perbedaan tingkatan/ derajat keduanya telah saling cinta mencintai, menyadari bahwa walaupun sang pemuda akan melamar tetapi lamaranya pasti tak akan diterima. ${ }^{17}$

\section{Nilariang}

Nilarian berati dilarikan. Si laki-laki secara paksa membawa si gadis kerumah penghulu adat (dalam hal ini imam atau kadhi) meminta perlindungan untuk dinikahkan.

Sebab-sebab khusus terjadinya nilariang ialah:

a. Pinangan ditolak oleh pihak keluarga perempuan sedangkan mereka dalam hubungan siratang. Penolakan pinangan dianggap sebagai suatu penghinaan besar bagi yang meminang, sehinggah sehinggah silelaki nekad dan memperlihatkan kekuatanya untuk dapat menutupi aib yang terjadi pada keluarganya.

b. Penghinaan langsung dari gadis yang bersangkutan, misalnya sigadis meluda tanda benci sewaktu dipandang oleh si lelaki. ${ }^{18}$

\section{Erangkale}

Erangkale artinya membawa diri. Perkawinan terjadi karena perempuan itu sendiri datang pada pihak lelaki untuk minta dikawini atau kerumah penghulu adat untuk meminta dikawinkan dengan lelaki yang tertentu yang dipilihnya.

Sebab-sebab terjadinya Erangkale ialah:

a. Karena pangngisengang(guna-guna), hal ini bisa terjadibila pemuda itu dihina baik oleh gadis itu sendiri maupun oleh keluarga gadis itu dan pemuda/ laki-laki itu tak dapat melarikan gadis itu secara paksa, maka ia melakukanya secara gaib dengan pangngisengang(guna-guna).

b. Karena sigadis telah melakukan hubungan rahasia sehinggah ia hamil atau dituduh melakukan hubungan gelap dengan seorang lelaki, sehinggah tak ada jalan lain baginya kecuali mendatangi laki-laki tadi untuk dikawini.

c. Menghindari kawin paksa, sehinggah sigadis mendatangi pemuda idamanya untuk minta dikawini.

Dengan uraian diatas jelaslah alasan-alasan yang menyebabkan terjadinya annyala yang merupakan suatu masalah yang menenimbulkan ketegangan di dalam masyarakat. Tiap Tu-Mannyala mempunyai niat kembali appala Bajik agar

\footnotetext{
${ }^{17}$ Ibid, Hlm 29

${ }^{18}$ Ibid, Hlm 30
} 
ia dapat hidup tidak tersisih dari keluarganya untuk selamanya. Oleh karena itu, bila si Tu-mannyalamampu dan berkesempatan untuk abbajik (berdamai) ia lalu minta bantuan kepada penghulu adat tempat ia minta perlindungan dahulu. Lalu diutuslah seseorang untuk menyampaikan maksud appala bajik (meminta damai) kepada keluarga/ tu-masirik yang selanjutnya menghubungi keluarga tu-masirik agar berkeinginan menerima kembali tu-tallasana(orang mati yang masih hidup)

Dalam hubungan ini keluarga tu-masirikmenyampaikan pada sanak keluarganya tentang maksud kedatangan tu-mannyala appala bajik (orang yang bersalah meminta perbaikan/ berdamai). Bila seluruh keluarga berkenaan menerima kembali tu-mannyala tersebut, maka hal ini akan disampaikan kepada yang mengurus, selanjutnya pada pihak tu-mannyala.

Si tu-mannyala menyediakan sunrang (mas kawin) sesuai dengan aturan sunrang menurut ketentuan sunrang wanita tersebut sebagaimana halnya dalam perkawinan adat. Selain sunrang, tu-mannyala juga menyediakan pappasala (denda karena berbuat salah). Pappasala dengan sunrang dimasukkan dalam sebuah tempat yang disebut kampu, disertai “leko'sikampu”(sirih pinang dalam kampu).

Suatu proses yang menyebabkan perkawinan selain yang telah diuraikan, ialah yang disebut dalam bahasa Makassar nipakatianang (hamil sebelum nikah). Kawin secara adat terlaksana apabila kehamilan siperempuan belum tersebar, baru diketahui oleh ibu dan kerabat wanita. Ibu yang terdekat sehinggah mereka berusaha secara rahasia berhubungan dengan keluarga si lelaki agar dalam tempo singkat perkawinan dapat dilangsungkan melalui prosedur yang biasa. Kedua bela pihak berusaha melindungi rahasia demi nama baik kedua keluarga.

Bilamana jalan pertama (kawin secara adat)gagal, maka terjadilah suatu prosedur yang sama dengan annyala, dalam hubungan ini keadaan perempuan lebih menyedihkan kalau silelaki tidak bertanggun jawab/ menhilang. Si perempuan yang berlindung kepada imam atau kadhi dengan seorang laki-laki yang sifatnya darurat. Lelaki yang menikahi seorang perempuan karena terlebi dahulu hamil yang sebelumnya tidak ada hubungan di sebut pa'tongko sirik (kawin penutup malu). Si perempuan yang bernasib sial ini oleh orang tuanya/ kerabatnya "niammateami". Adapun anak yang dilahirkan kemudian disebut anak bule (=anak haram jadah). Anak yang demikian bila hidup sampai besar sangat sulit kedudukanya dalam masyarat, karna seola-olah anak bule itulah yang 
menanggung segala konsekuensinya atau kesalahan dan dosa daripada ibu dan lelaki yang bertanggun jawab itu.

5. Syarat-Syarat Untuk Kawin

Persyaratan bagi seorang yang akan kawin lebih banyak dikenakan kepada pihak lelaki. Seorang lelaki yang akan kawin selain persiapan yang berupa materi untuk pelaksanaan perkawinan ia harus pula melengkapi diri dengan pengetahuanpengetahuan tentang hubungan kerumah-tanggaan, sebab kekurangan-kekurangan yang akan terjadi dalam rumah tangga, kesalahnya kebanyakan dilimpahkan kepada lelaki, misalnya istrinya sakit-sakitan dan sebagainya. Seorang suami harus mengetahui bagaimana membina ruamah tangga dan terutama keselamatan istrinya. Hal ini dalam bahasa Makassar dikatakan: Naeroi pallua pintuju (mengitari dapur tujuh kali). ${ }^{19}$

6. Upacara Perkawinan

a. Upacara Sebelum Perkawinan

Acara peminangan melalui beberapa fase dan di mulai dengan Accini'rorong, artinya melihat atau mencari jalan sebagai penyelidik. Usaha semacam ini adalah untuk mengetahui secara rahasia tentang kemungkinanya laki-laki mengajukan lamaran pada gadis yang dipilih. Usaha penyidikan juga bermaksud untuk mengetahui sifat-sifat, tingkah laku, budi bahasa, dan sebagainyadari gadis itu kalau penyelidikan berhasil dalam usahanya, maka dilanjutkan fase berikutnya yaitu dengan appesak-pesak. Appesak-pesak artinya meraba-raba, dalam hal ini diutus seorang perempuan kepercayaan yang pandai bersiasat. ${ }^{20}$

Pada hari yang telah ditentukan sanak keluarga gadis bersama-sama menanti kedatangan delegasi pihak laki-laki. Pemimpin delegasi menyampaikan salam hormat dari orang tua si...... dan selanjutnya menyampaikan maksud kedatanganya. Pada saat itu terjadila perundingan dan apabila telah tercapai kata sepakat dari pimpinan. Pada waktu apparassa ini yang menjadi acara pembicaraan, ialah segala sesuatu yang ada hubunganya dengan pelaksanaan perkawinan nanti angtara lain; Sunrang, doe balanja/ ongkos perkawinan, penentuan hari perkawinan.

a) Sunrang

Sunrang adalah mas kawin. Syarat mutlak menurut hukum islam yang dilaksanakan oleh orang-orang islam di manapun juga. Sunrang ialah pemberian

\footnotetext{
${ }^{19}$ Ibid, Hlm 33.

${ }^{20}$ H. Saharuddin, Susunan dan Sistem Pemerintahan Kerajaan Balangnipa Dahulu, Dalam Hubunganya Dengan Kebudayaan Bandar Sulawesi Selatan tahun 1997. Yayasan Kebudayaan Sulawesi Selatan. Hlm. 78
} 
dari pihak laki-laki kepada wanita yang dikawini. Sunrang ini dapat berupa uang ataupun borang.

b) DoE Balanja

Besar kecilnya uang balanja ini tergantung dari kesepakatan kedua bela pihak.namun tidak pula dapat di sangkal bahwa masalah uang balanja yang sangat tinggi sehinggah sering perkawinan tidak dapat dilaksanakan.

Selain dari pada uang balanja, ada pula yang disebut Cikarrang, ini berupa hadiah-hadiah yang sebentar juga mendapat balasan hadiah dari pihak perempuan. Cingkaran = pemberian hadiah-hadiah dari kedua bela pihak kepada bakal menantu masing-masing, dan hadiah-hadiah yang berupa borang perihasan emas dan lain-lainya akan menjadi "borang-borang sisila" yakni harta bawaan bagi kedua orang suami istri. Sebelumnya pihak laki-laki telah mengundang sanak keluarganya untuk bersama-sama mengantar Leko caddi (sirih kecil) kerumah pihak perempuan. Demikia pula pihak perempuan mengundang sanak keluarganya untuk bersama-sama menantikan kedatangan tamunya dalam rangka peresmian waktu pelaksanaan perkawinan.

Upacara Appanai loko lompo (upacara menaikkan sirih besar). Tujuh atau tiga hari sebelum pernikahan Leko Lompo diangtarkan dari pihak lelaki kerumah pihak perempuan (calon pengantin perempuan). Kalau uang belanja belum diantarkan/ diserahkan pada waktu appanai leko caddi, maka disertakan dalam appanai leko lompo. Yang diangtarkan yaitu:

- Sirih pinang lengkap terdiri dari daun sirih beberapa $k a$ 'bak (ikat) pinang bertandang (rappo appae), tembakau, gambir, kapur secukupnya.

- Gula merah beberapa biji, keloapa bertanda, pisang bertandan, dan beberapa buah-buahan yang lain.

- Segala macam kue adat yang simpan dalam bosarak yaitu: lobo, sekroksekrok, cucuru, rokok-rokok cangkuning, dll.

- Perlengkapan pakaian perihasan dan alat-alat kecantikan. Setiap bossara dibawah oleh seseorang yang berpakaian adat.

b. Upacara Perkawinan

Bahwa perkawinan adalah suatu peralihan dari periode sebelum kawin ke periode sesudah kawin juga harus melalui upacara. Dalam penulisan ini upacara pelaksanaan perkawinan dimulai dengan akad nikah dan pertemuan angtara penganting laki-laki dan perempuan seterusnya sampai ni'pa'bajikang (didamaikan). 
Naikkalena adalah saat pengantin laki-laki dan perlengkapanya dalam upacara nikah yang telah disediakan pada malamnya (berpacar) diarak kerumah pengantin perempuan sunrang yang sudah tertentu dimasukkan kedalam kampu yang dibungkus dengan kain putuh digendong (dibawah) oleh orang tua yang berpakaian adat. Isi kampu disebut "Loro Sunrang” yang terdiri dari beras segenggam kunyit serangkai, simbol supaya banyak anak. Menjelan rumah pengantin perempuan arakarakan disongsong oleh orang yang berpakaian adat yang juga dimeriahkan dengan bunyi-bunyian yang serupa, setelah sampai dimuka tangga dan pada saat bunyi ganrang tunnung pakaniara (pukulan gendang yang sangat bersemangat) selesai, keluarlah seorang perempuan yang agak tua diambang pintu lalu memanggil/ mengambil pengantin dengan susunan kata-kata yang tentu seperti nyayian disebut $P a$ ' kiyo bunting sambil menghamburkan beras.

Kemudian naiklah pengantin laki-laki dengan pergirinya dan duduk pada tempat yang telah disediakan dimana imam/ kadhi serta sanak keluarga (wali) pengantin perempuan telah menanti, maka upacarah akad nikahpun berlangsunglah dengan pernyataan ijab kabul dengan wali pengantin perempuan dan pengantin laki-laki. Sesaat setelah akad nikah sudah berlangsung diadakanlah pertemuan angtara pengantin laki-laki menuju kamar pengantin perempuan diangtar oleh orang-orang tertentu yang dianggap bertuah dalam kehidupan rumah tangganya, dan sebagainya untuk appabattu nikka. Di pintu kamar biasanya pengantin tidak langsun masuk karna ditahan/ dihalangi oleh penjaga pintu dan baru diloloskan setelah diberikan uang berupa tebusan yang disebut panyyungke pakkebbu dan apabila penganitin lelaki berasal dan daerah lain ia pun membayar tebusan yang disebut pallawa pa' rangsangan (penghalang negeri), sementara itu penganti perempuan oleh anrong buntingan (tukan rias pengantin) dipakaikan bermacam-macam alat yang mengandung hikmah tertentu. Dalam appabattu nikka ada yang memegang/ menyentuh salah satu anggota tubuh perempuan, biasanya yang dipegang adalah buah dada pengantin perempuan sebagai simbol seperti gunung, supaya kelak rezkinya menggunung seperti gunung, dan menurut anggapan mereka disinilah terletak fungsi bahagian tubuh yang terpenting yaitu sumber makanan pertama kali jika manusia baru dilahirkan, dan ada juga pertama-tama meraba ubun-ubun, atau leher bahagian belakang, maknanya supaya wanita tunduk pada suaminya, adapula yang pertama-tama memegan tangan istrinya atau pengantin perempuan maknanya supaya kekallah hubungan keduanya. 
7. Ciri Khas Perkawinan Adat Bugis Makassar

Sebagaimana telah dijelaskan pada pendahuluan bahwa pernikahan adat budaya bugis Makassar adalah salah satu budaya pernikahan di Indonesia yang paling kompleks dan melibatkan banyak emosi, mulai dari ritual lamaran hinggah selesai resepsi pernikahan akan melibatkan seluruh keluarga yang berkaitan dengan kedua pasangan calon mempelai.

Pernikahan adat Bugis Makassar masih sangat kental dengan budaya-budaya mereka dan akan sarat makna dengan ritual-ritual yang dilaksanakan. Mereka sangat meyakini dan mempercayai akan makna yang terkandung dengan tradisi-tradisi mereka, mulai dari tahap perencanaan sampai pada berlangsungnya penikahan akan dibumbuhi kehati-hatian dan takut melanggar apa yang menjadi kepercayaan mereka.

Ciri khas pernikahan adat Bugis Makassar akan nampak pada upacara-upacara sesudah akad nikah dan ini dipenuhi dengan makna yang sangat sakral. Pengantin lakilaki dengan beberapa pengirinya tinggal bermalam semalam atau tiga malam dirumah istrinya, esok harinya biasanya menjelang tengah hari diadakan upacara mandi yang disebut aje'ne je'ne. Pengantin dengan semua orang yang ada dirumah bersiramsiraman tanpa memperhatikan basahnya pakaian dan seluruh rumah dan isinya. Semalam atau beberapa malam pengantin lelaki dirumah istrinya lalu diarahkanlah kedua pengantin kerumah pengantin laki-laki yang disebut"rillekka". Sesampai dimuka tangga arak-arakan berhenti sebgaimana halnya pada waktu simorong dan turunlah dari tetangga kerabat terdekat atau ibu pengantin laki-laki menjemput menantunya dan memanggil untuk naikkerumah dengan pakpaenteng panggilan diiringi dengan pemberian. Setelah pengantin naik kerumah duduklah pada tempat yang telah disediakan dimana tamu-tamu berdatangan terus berlangsunglah pula periamuan sebagaimana halnya dirumah pengantin dirumah perempuan. ${ }^{21}$

Semalam atau beberapa malam pengantin perempuan, dirumah mertuanya ia memohon diri untuk kembali kerumahnya yang disebut appalak kana, ia pun mempersembahkan lipak sarung tenungan yang dibalas pula dengan pemberianpemberian. Upacara nipak bajikan ini diadakan karna pada zaman dahulu angtara pengantin laki-laki dan perempuan tidak saling mengenal sehinggah perempuan masih malu untuk berbicara, bahkan bertemu muka sekali pun dan berakhirlah upacara perkawinan secara resmi.

\footnotetext{
${ }^{21}$ Dinas Kebudayaan dan Parawisata.....Hlm. 55
} 


\section{KESIMPULAN}

Perkawinan merupakan suatu peristiwa yang sangat penting dalam kehidupan manusia. Dalam ajaran Islam pun kita di anjurkan untuk menikah, Al-Qur'an pun menjelaskan dalam surah Az-Zariyah ayat 49, dan surah yasin ayat 36, bahwa manusia telah diciptakan dalam bentuk pasangan-pasangan, baik dari apa yang ditumbuhkan oleh bumi dan dari diri mereka maupun dari apa yang tidak mereka ketahui.

Tujuan perkawinan menurut agama islam ialah untuk memenuhi petunjuk agama dalam rangka mendirikan keluarga yang harmonis, sejahtera dan bahagia. Harmonis dalam menggunakan hak dan kewajiban anggota keluarga, sehinggah timbullah kebahagiaan, yakni kasih sayang angtar anggota keluarga. Begiru pula dalam budaya Bugis Makassar perkawinan adalah salah satu cara untuk melanjutkan keturunan dengan dasar cinta kasih untuk melanjutkan hubungan yang erat angtara keluarga yang lain, angtara suku dan suku yang lain bahkan angtara bangsa dengan bangsa lain.

Dalam budaya adat Bugis Makassar dikenal pula perkawinan ideal dan pembatasan jdoh yaitu perkawinan angtara Sampo Sikali (sepupu satu kali), hubungan perkawinan ini disebut sialleang baji'na (perjodohan yang paling baik), perkawinan angtara Sampo Pinruang (sepupu dua kali), hubungan perkawinan ini disebut nipassikaluki, perkawinan angtara sampo pintallu (sepupu tiga kali), dan seterusnya. hubungan perkawinan ini disebut nipakambani bellayua (yang jauh didekatkan). Dalam budaya adat Bugis Makassar ada beberapa bentuk-bentuk perkawinan, mulai dalam bentuk peminangan, perkawinan dengan annyala, silariang, nilariang,dan erangkale

Upacara perkawinan di daerah Sulawesi Selatan banyak dipengaruhi oleh ritualritual sakral dengan tujuan agar perkawinan berjalan dengan lancar dan kedua mempelai mendapat berkah dari Tuhan. Semua itu dilakukan mempunyai makna dan kepercayaan tersendiri. 


\section{DAFTAR PUSTAKA}

Abdul Rahman, Fiqh Munakahat, (Cet, IV, Jakarta: Kencana, 2010 )

Cholil Mansyur, Sosiologi Masyarakat Kota dan Desa, (Surabaya : Usaha Nasional, 1994)

Departemen Agama RI, Al-Qur'an dan Terjemahanya, CV Penerbit J-ART, Bandun, 2005

Dinas Kebudayaan dan Parawisata Propinsi Sulawesi Selatan, Adat dan Upacara Perkawinan Daerah Sulawesi Selatan. 2006.

H. Saharuddin, Susunan dan Sistem Pemerintahan Kerajaan Balangnipa Dahulu, Dalam Hubunganya Dengan Kebudayaan Bandar Sulawesi Selatan tahun 1997. Yayasan Kebudayaan Sulawesi Selatan.

Petadungan dan kk, Catatan Perkawinan . Tahun 1969.

Titik Triwulan dan Trianto, Poligami Perspektif, Perikatan Nikah, (Jakarta : Prestasi Pustaka, 2007). 